\title{
The Role of Steroids and Hormones in Gynecomastia-Factors and Treatments
}

Pooja Shree*

Department of Biotechnology, SSIET-Anna University, Chennai, India

"Corresponding author: Pooja Shree, Department of Biotechnology, SSIET-Anna University, Chennai, India, E-mail: Shrithushree@gmail.com

Received date: September 21, 2018; Accepted date: October 5, 2018; Published date: October 12, 2018

Copyright: (C2018 Shree P. This is an open-access article distributed under the terms of the Creative Commons Attribution License, which permits unrestricted use, distribution, and reproduction in any medium, provided the original author and source are credited

\begin{abstract}
Gynecomastia is an endocrine disorder where the male breast tissue swells and growth in the size abnormally. All men and women have breast glands; however they're no longer significant in males, because they have a tendency to be small and undeveloped. Drugs which include steroids motive $10 \%-25 \%$ of cases of gynecomastia. They throw off the hormonal stability which increases in estrogen (the female sex hormone) and/or a lower in testosterone (the male sex hormone), which reasons the breast tissue to develop. Almost all reasons of gynecomastia may be in a single manner or different much like excess production of the hormone estrogen inside the male frame because of different factors. In this article, we overview the reasons and treatment of gynecomastia.
\end{abstract}

Keywords: Estrogen; Gynecomastia; Steroids; Breast tissue

\section{Introduction}

Gynecomastia is a benign growth of the male breast tissue. Gynae which means "lady" and mastos means "breast" in Greek. It can be characterized as the nearness of $>2 \mathrm{~cm}$ of palpable, firm and ductal breast tissue. Before digging profound into the reasons for gynecomastia, let's get straight about what is gynecomastia and what it isn't. Breast enlargement in male caused by inordinate bosom tissue development is authentic gynecomastia. Breast enlargement in men can likewise be caused by fat being developed behind and around the areola and this is to be recognized from pseudogynecomastia or adipomastia or lipomastia. This is to be prominent from pseudogynecomastia, which lacks presence of this sort of disk of tissue, as it is a boom in sub areolar fat without growth of the breast glandular aspect [1-3].

Gynecomastia is found in $60 \%-90 \%$ of newborns and commonly resolves spontaneously within few weeks. Most pubertal young men create gynecomastia, by the age of 14 years $60 \%$ of boys have gynecomastia. Beyond the pubertal age, gynecomastia is found in $33 \%-41 \%$ ordinary men matured $25-45$ years and in $55 \%-60 \%$ of men over the age of 50 years (Figure 1).

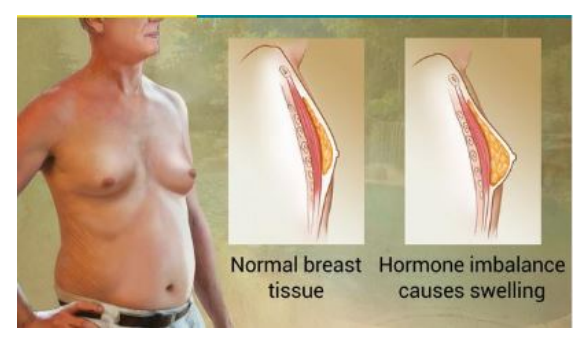

Figure 1: Swollen male breast tissue caused by a hormone imbalance.

\section{Gynecomastia pathophysiology}

The imbalance between estrogen actions relative to androgen action at the breast tissue level appears to be the main etiology of gynecomastia.

Depending on the hormonal conditions within the body, any demanding elements, and other issues will determine the rate of progression within the improvement of gynecomastia and the depth and severity of the formation of breast tissue include: The sort of anabolic steroid(s) utilized, measurements of anabolic steroids utilized, span of utilization of the anabolic steroids, and perhaps the most critical persuasive deciding component, personal individual hereditary qualities and responsiveness $[4,5]$.

\section{Steroidal abuse}

Steroid clients are one of the sub bunches among men who have gynecomastia. The un-methodical utilization of it is the thing that causes gynecomastia. When a steroid client begins his cycle, the regular hormonal adjust in his body is changed by concealment of the creation of the male hormone testosterone. This triggers a progression of chain response coming full circle in the improvement of gynecomastia.

Not all steroids prompt Gynecomastia, but rather they all have their consequences. Anadrol and Dianabol are large reasons for Gynecomastia, yet there are others. Estrogen goes about as the essential offender in the arrangement and the advancement of gyno where it will append to the Estrogen receptors situated on cells inside breast tissue and signal growth. What comes about is then a continuous improvement of greasy tissue, stringy tissue, and glandular tissue that inevitably after some time will detail full Gynecomastia [6-11].

\section{Hormonal imbalance}

All individuals regardless own both female sex hormones (estrogens) and male sex hormones (androgens). During pubescence, levels of these hormones may change and ascend at various levels, 
Page 2 of 4

bringing about a transitory state in which estrogen fixation is tremendously high. Gynecomastia caused by temporary adjustments in hormone tiers with increase usually disappears on its own within six months to 2 years. Occasionally, gynecomastia that develops in pubescence holds on past two years and is called persistent pubertal gynecomastia [12-14].

\section{Low testosterone levels}

Illegal testosterone medications utilized for building up can cause breast development in males. Anabolic steroids are manufactured synthetic variants of testosterone. While testosterone treatment can assist enhance your sexual coexistence, muscle mass, vitality, disposition and it could also purpose some transient breast development. This is on account of all men have an enzyme called aromatase that converts testosterone to a shape of estrogen. Taking a medication to hinder the transformation of testosterone to estrogen additionally is certifiably not a smart thought [15-18].

\section{High estrogen levels}

The female sex hormone estrogen inside the male may cause the breast development. It may be over abundance estrogen persisted from pubescence, due to a pre-current medical circumstance, as a reaction of medicines or because of drug abuse. Once there is an abundance of estrogen, it sets off a sequence response with the aid of decreasing the generation of testosterone and bringing down digestion. Abundance estrogen will likewise signal the body to hold more fat in the chest and in the belly. When fat is stored in the chest and belly, they emit a catalyst called aromatase that converts testosterone to estrogen. So pectoral fat basically turns into an auxiliary organ that produces estrogen [19-21].

\section{Medical Conditions that Can Cause Gynecomastia}

Around $20 \%$ of gynecomastia is caused by medications or exogenous chemicals. Drugs and chemicals that cause decreased testosterone levels either by causing direct testicular damage, by blocking testosterone synthesis, or by blocking androgen action can produce gynecomastia. For instance, phenothrin, a chemical component in delousing agents, possessing antiandrogenic activity, has been attributed as the cause of an epidemic of gynaecomastia among Haitian refugees in US detention centers in 1981 and 1982. Chemotherapeutic drugs, such as alkylating agents, cause Leydig cell and germ cell damage, resulting in primary hypogonadism.

One of the traditional examples of a scientific condition that motives gynecomastia is Klinefelter Syndrome. This disorder is described by a chromosomal oddity with men having an extra $\mathrm{X}$ chromosome. Studies have demonstrated that men with this medicinal condition have gynecomastia as a typical side effect [22-24].

\section{Hyperthyroidism}

The thyroid organ is in charge of the creation of thyroid hormones and hyperthyroidism takes place when this gland turns over-energetic. Hyperthyroidism is sexually unbiased and can happen to the two people yet in men, it is considered as one of the reasons of gynecomastia. Early recognition of this condition and auspicious intercession has been located to effectively reverse gynecomastia $[25,26]$.

\section{Kidney failure}

Kidney failure is one of the medicinal conditions that can cause gynecomastia when our kidneys can't do their ordinary sifting process, it triggers a progression of bodily reactions and hormonal brokenness is one among them. The final product is a concealment of the generation of Testosterone. In this situation, estrogen levels tip the hormonal stability inflicting gynecomastia.

\section{Treatment and Medication}

Treatment of Gynecomastia is not constantly important. It relies on its motive, period, and severity and whether it causes agony or uneasiness. Since early stages of gynecomastia happens in puberty stage, normally resolves on its very own without treatment within three years in $90 \%$ of cases, no active remedy is needed. But if the breast increases $>4 \mathrm{~cm}$ in measurement may not be reduced totally. If medicines are the reason for gynecomastia, halting the culpable medication can be effective in decreasing gynecomastia. Treatment of any basic therapeutic conditions is likewise imperative. Both pharmaceuticals and surgical procedures have been effectively used to treat gynecomastia [27-29].

Once gynecomastia is established, testosterone treatment of hypogonadal men with gynecomastia often fails to produce breast regression. Unfortunately, testosterone treatment may actually produce the side effect of gynecomastia by being aromatized to estradiol. Thus, although testosterone is used to treat hypogonadism, its use to specifically counteract gynecomastia is limited. Dihydrotestosterone, a non-aromatizable androgen, has been used in patients with prolonged pubertal gynecomastia with good response rates.

From previous series, the patients with gynecomastia show no significant improvement after the medications. This may be related to the stage of disease at which medical treatment is initiated. It has been suggested that the patient with a long history of gynecomastia, in which the breast tissue becomes fibrotic, tends to be resistant to medical treatment.

\section{Breast surgery}

Reduction mammoplasty is taken into consideration for patients with macromastia or long-status gynecomastia or in persons in whom medical therapy has failed. Minimally invasive surgery is available and it may be associated with few complications and prompt recovery.

It is also considered for beauty reasons. The aims of surgery are: (1) to get rid of painful breast tissue. (2) To restore the patient's chest to acceptable beauty form. Complications of surgical procedure consist of removal of tissue because of a compromised blood supply, contour irregularity, hematoma or sarcoma formation, and everlasting numbness inside the nipple-areolar place, doughnut deformity, nipple necrosis, nipple flattening [30].

\section{Liposuction}

This surgical procedure removes breast fats, but no longer the breast gland tissue itself. Liposuction/lipoplasty ("fat modeling") is best remedy as it is associated with few sequelae. In this technique, a limited cannula is embedded in breast tissue and used to vacuum fat tissue after that cannula pushed and pulled to break all adipocytes and suctioning them out. This method is known as suction-helped liposuction [31,32]. 


\section{Mastectomy}

The commonly utilized method is subcutaneous mastectomy that includes coordinate resection of the glandular tissue utilizing a periareolar or trans-areolar approach, with or without liposuction. Liposuction alone might be adequate if bosom growth is absolutely because of overabundance greasy tissue without considerable glandular hypertrophy. This less invasive sort of surgical operation entails much less recovery time [33].

\section{Selective estrogen receptor modulators (SERMs)}

SERMs are tamoxifen and raloxifene can help reduce the amount of breast tissue, even though they are not ready to completely dispense with the issue [34]. Tamoxifen, an estrogen antagonist, is effective for recent-onset and gentle gynecomastia Up to $80 \%$ of patients report partial to finish resolution. These medicinal drugs are most often used for excessive or painful gynecomastia With the management of clomiphene, an antiestrogen about $50 \%$ of sufferers acquire partial diminishment in breast size, and approximately $20 \%$ of patients observe entire resolution. Adverse outcomes are uncommon and consist of visual problems, rashes, and nausea. Other capsules used, albeit less often, includes danazol [35]. Danazol, a synthetic subsidiary of testosterone, inhibits pituitary secretion of $\mathrm{LH}$ and folliclestimulating hormone (FSH), which decreases estrogen synthesis from the testicles [36].

\section{Radiotherapy}

Radiation therapy is compelling for counteractive action, and treatment of gynecomastia, caused by androgen ablation in sufferers of prostate tumor. Radiation treatment is more successful if given prophylactically before administration of hormone therapy. However, it has been utilized with some achievement in overseeing painful gynecomastia [37].

\section{Discussion}

Gynecomastia associated with medicinal conditions can be counteracted by using appropriate therapeutic interventions or via avoidance of the incriminated agent. When age-associated hormonal fluctuations result in gynecomastia, it isn't avoidable prophylactically [38]. When administering lengthy-time period hormonal remedy to prostate most cancer sufferers, prophylactic irradiation of bilateral breasts can save you subsequent development of gynecomastia [27].

Making intelligent lifestyle choices offers the best option for preventing gynecomastia not associated with an underlying disorder. Various factors have been tied to imbalances in hormones. Body builders should avoid anabolic steroids that disturb hormone production and cause other health problems [39]. Use of marijuana has been connected with increased levels of estrogen. Proper diet and exercise can reduce the risk of pseudogynecomastia, the buildup of fat tissue. Prevention of gynecomastia caused by other therapies or underlying disorders may be possible with medications that reduce the effect those factors have on male and female hormones [40].

\section{Conclusion}

Treatments for gynecomastia have now not been drastically studied, No tablets have yet been permitted by using the U.S. Food and Drug Administration for remedy of gynecomastia. Fortunately, in lots of instances, gynecomastia resolves spontaneously without the want for unique remedy. Medical and surgical remedies can be effective for continual gynecomastia. Typically gynecomastia is itself not threatening; however guys with gynecomastia have an improved hazard (approximately five-fold) for growing male breast cancer when as compared with the general population. It is possibly that the hormonal adjustments that produce gynecomastia in male additionally boom their danger of developing breast most cancers. This is a commonly identified entity and consciousness to diagnose and attention to analyze and treat it properly is justified.

\section{References}

1. Yordanov YP, Shef A (2017) Acute tissue trauma as a trigger for gynecomastia development and progression. J Trauma Treat 6: 409.

2. Sankaranantham M (2017) Hypogonadism and gynecomastia in 3 adolescent boys on ART- 3. HIV Curr Res 2: 123.

3. Bhattacharya SK (2016) Gynecomastia in a young male. J Mol Imag Dynamic 6: 106.

4. Campos PMR, Rosa BP, Barros AS, Karmali S, Almeida JF, et al. (2017) A rare case of bilateral patellar tendon rupture associated with anabolic androgenic steroids use. Orthop Muscular Syst 6: 238 .

5. Nuzzi R, Dallorto L (2017) Efficacy and safety of combined intravitreal bevacizumab and retrobulbar corticosteroids for neovascular age-related macular degeneration. J Clin Exp Ophthalmol 8: 659.

6. Somani S, Meghani S (2016) Substance abuse among youth: a harsh reality. Emerg Med (Los Angel) 6: 330.

7. Giardino PA (2016) Child abuse and neglect: Are cases increasing or decreasing after 50+ years of paediatric attention? Clinics Mother Child Health 13: 235.

8. Linder JM, Silverstone PH (2016) Initial long-term findings from a multimodal treatment program for child sexual abuse victims demonstrate reduction of ptsd frequency and symptoms. J Child Adolesc Behav 4: 297.

9. Ahmadi J (2016) Conduct disorder related to poly substance abuse in adolescence. J Psychiatry 19: 371.

10. Raiker N, Aouthmany M, Ezra N (2016) Dermatologic signs and symptoms of substance abuse. J Clin Exp Dermatol Res 7: 337

11. Carmen M Sarabia-Cobo (2016) Screening and interventions in elderly abuse. Glob J Nurs Forensic Stud 1: e104.

12. Onwubuya EI, Ukibe NR, Kalu OA, Agbo BS, Ukibe SN, et al. (2018) Assessment of the effects of oxidative stress on some reproductive hormones in male hypertensive subjects at nauth, nnewi. J Bioanal Biomed 10: 64-69.

13. Kelleni MT (2017) Diabetogenic drugs and hormones, what every physician should know and be aware of ? Gen Med (Los Angeles) 5: e114.

14. Ginneken VV, Ham L, de Vries E, Verheij E, van der Greef J, et al. (2016) Comparison of hormones, lipoproteins and substrates in blood plasma in a c57bl6 mouse strain after starvation and a high fat diet: A metabolomics approach. Anat Physiol 6: 233.

15. Azad N, Sakla N, Bahn G (2018) The effect of testosterone replacement therapy on glycemic control in hypogonadal men with type 2 diabetes mellitus. J Clin Diabetes 1: 101.

16. Hadlow N, Hamilton K, Joseph J, Millar D, Zentner A, et al. (2017) Relationships between anti-mullerian hormone, testosterone, luteinizing hormone and follicle stimulating hormone in men on testosterone therapy. Clin Med Biochem 3: 128.

17. Ueshiba $H$ (2017) The efficacy of testosterone ointment on insulin resistance in men with metabolic syndrome. J Metabolic Synd 6: 225.

18. Gunnels TA, Bloomer RJ (2014) Increasing circulating testosterone: impact of herbal dietary supplements. J Plant Biochem Physiol 2: 130.

19. Zhang K (2014) Epigenetic reprogramming induced by environmental estrogens. Mol Biol 3: el15. 
Citation: Shree P (2018) The Role of Steroids and Hormones in Gynecomastia-Factors and Treatments. J Steroids Horm Sci 9: 195. doi: 10.4172/2157-7536.1000195

Page 4 of 4

20. Bazin I, Hassine AIH, Mnif W, Gonzalez C (2013) YES as a tool for detecting estrogenic activity of some food additives compounds: E 104, E 122, E 124, E 132 and E 171. J Ecosys Ecograph 3: 128.

21. Suba $Z$ (2013) Low estrogen exposure and/or defective estrogen signaling induces disturbances in glucose uptake and energy expenditure. J Diabetes Metab 4: 272.

22. https://www.mayoclinic.org/diseases-conditions/gynecomastia/ symptoms-causes/syc-20351793

23. https://www.gynecoma.com/gynecomastia-diagnosis-treatment/

24. Väre T, Galassi FM, Niinimäki J, Junno JA (2018) Potential case of gynecomastia in mummified remains of an early modern period northern finnish vicar. Clin Anat 31: 641-644.

25. Arya R, Rathi AK, Singh K, Srivastava A, Panda D, et al. (2016) Gynecomastia: A review of literature. MAMC J Med Sci 2: 69-75.

26. Al Jurayyan NA (2016) Childhood gynecomastia: a mini review. Int J Clin Endocrinol Metab 2: 012-015.

27. Cuhaci N, Burcak Polat S, Evranos B, Ersoy R, Cakir B (2014) Gynecomastia: Clinical evaluation and management. Indian J Endocrinol Metab 18: 150-158.

28. Arvind A, Abbas Khan MA, Srinivasan K, Roberts J (2014) Gynaecomastia correction: A review of our experience. Indian J Plast Surg 47: 56-60.

29. Narula H, Carlson H (2014) Gynaecomastia- pathophysiology, diagnosis and treatment. Nat Rev Endocrinol 10: 684-698.
30. Mangla M, Singla D (2017) Gestational gigantomastia: A systematic review of case reports. J Midlife Health 8: 40-44.

31. Moskovitz MJ, Baxt SA, Jain AK, Hausman RE (2007) Liposuction breast reduction: a prospective trial in african american women. Plast Reconstr Surg 119: 718-726.

32. Bellini E, Grieco MP, Raposio E (2017) A journey through liposuction and liposculture: Review. Ann Med Surg (Lond) 24: 53-60.

33. Lazaraviciute G, Chaturvedi S (2017) Mastectomy-a critical review. J Clin Diagn 7: 58-66.

34. Maximov PY, Lee TM, Jordan VC (2013) The discovery and development of selective estrogen receptor modulators (serms) for clinical practice. Curr Clin Pharmacol 8: 135-155.

35. Goodsell DS (2002) The molecular perspective: tamoxifen and the estrogen receptor. The Oncol 7: 163-164.

36. Dmowski WP (1990) Danazol, a synthetic steroid with diverse biologic effects. J Reprod Med 35: 69-74.

37. Luh JY, Harmon MW (2010) Radiation therapy for gynecomastia. Mayo Clin Proc 85: 398-399.

38. Johnson RE, Murad HM (2009) Gynecomastia: Pathophysiology, evaluation, and management. Mayo Clin Proc 84: 1010-1015.

39. Sansone A, Romanelli F, Sansone M, Lenzi A, Di Luigi L (2017) Gynecomastia and hormones. Endocrine 55: 37-44

40. Carlson HE (2011)Approach to the patient with gynecomastia. J Clin Endocrinol Metab 96: 15-21. 